Journal of Molecular Structure, 63 (1980) 249-258

() Elsevier Scientific Publishing Company, Amsterdam - Printed in The Netherlands

\title{
STRUCTURE OF TRI-TERT-BUTYLSILANE BY ELECTRON DIFFRACTION AND MOLECULAR MECHANICS
}

\author{
S. K. DOUN and L. S. BARTELL \\ Department of Chemistry, University of Michigan, Ann Arbor, Michigan 48109 (U.S.A.)
}

(Received 3 September 1979)

\section{ABSTRACT}

A model force field for silanes is constructed by extending the model field MUB-2 to include silicon, for the following purposes: the calculation, via normal coordinate analyses, of amplitudes of vibration and shrinkage corrections for use in gas-phase electrondiffraction analyses, and the calculation of molecular structure by means of molecular mechanics. All of these applications are carried out in conjunction with an electrondiffraction study of $\left[\left(\mathrm{CH}_{3}\right)_{3} \mathrm{C}\right]_{3} \mathrm{SiH}$. Evidence of significant steric strain is obtained in both the diffraction and the molecular-mechanics investigations. Diffraction results include the structural parameters $( \pm 3 \sigma) r_{\mathrm{g}}(\mathrm{Si}-\mathrm{C})=1.934(6) \AA, r_{\mathrm{g}}(\mathrm{C}-\mathrm{C})=1.548(3) \AA, r_{\mathrm{g}}(\mathrm{C}-\mathrm{H})=$ $1.121(9) \AA, \angle H S i C=105.3(1.3)^{\circ},(\angle S i C C)_{\mathrm{av}}=111.5(0.5)^{\circ}, \angle C C H I=110.0(1.5)^{\circ}, t-b u t y l$ torsion $=10(3)^{\circ}, t$-butyl tilt $=2.7(2.4)^{\circ}$. Experimental and calculated structures and amplitudes are in satisfactory agreement. The present compound is found to be appreciably less strained than its hydrocarbon analog $\left[\left(\mathrm{CH}_{3}\right)_{3} \mathrm{C}\right]_{3} \mathrm{CH}$, somewhat more strained than $\left[\left(\mathrm{CH}_{3}\right)_{3} \mathrm{Si}\right]_{3} \mathrm{CH}$, and much more strained than $\left[\left(\mathrm{CH}_{3}\right)_{3} \mathrm{Si}\right]_{3} \mathrm{SiH}$. Molecularmechanics results are presented for the present compound and its carbon and silicon analogs.

\section{INTRODUCTION}

Several years ago a structure determination was carried out on the highly crowded molecule tri-t-butylmethane (TTBM) in the vapor phase $[1,2]$. The study was unusually rewarding because the effects of steric hindrance upon its structure afforded one of the most stringent tests to date of non-bonded interactions in the various model force-fields proposed for use in "molecular mechanics" calculations. Furthermore, because of its high symmetry, the molecule is extremely simple for one of such great congestion and, accordingly, it could be studied with some precision by electron diffraction. Therefore, when the silane analog tri-t-butylsilane (TTBS) became available it seemed of interest to subject this compound to an electron-diffraction investigation. The compound had eluded synthesis until 1975 when Doyle and West [3] devised a successful procedure.

Of the model force fields in existence when the structure of TTBM was determined, the modified Urey-Bradley field MUB-1 [4] gave a better account of the results than most others, despite its greater simplicity and its 
total lack of empirically-adjusted potential parameters. Several years later an improved field MUB-2, of similar conception, was formulated for hydrocarbons [5]. In view of the increasing interest in structural studies of organosilicon compounds, as exemplified by the present study, it was thought desirable to extend the field MUB-2 to include silicon. Such an extension is reported here. One incentive was to acquire a predictive tool for molecular structure, though a more practical reason of immediate utility for the present study was to provide a means for estimating amplitudes of vibration and shrinkage corrections through normal coordinate calculations. As will be discussed in the following, reasonable estimates of certain amplitudes are essential in the case of an analog of TTBS if a unique least-squares minimum is to be established.

\section{EXPERIMENTAL}

The sample of tri-tert-butylsilane was prepared by Dr. P. H. Nowakowski in Professor L. M. Sommer's laboratory. IR and vapor pressure studies revealed no contaminants. A high-temperature nozzle system of a type described elsewhere [6] was employed. Diffraction data were recorded on $4 \times 5$ in. Kodak electron image plates. The experimental conditions are outlined in Table 1.

The reduction of photographic data was performed as described elsewhere [7]. Tabulated elastic scattering factors due to Schäfer et al. [8] and inelastic scattering factors from Tavard et al. [9] were used in computations of theoretical intensities. Morse asymmetry parameters, $a$, (used as if each distribution peak were that of a ground-state oscillator) were taken as $2 \AA^{-1}$ for each bonded distance and zero for non-bonded distances.

\section{ANALYSIS OF DATA}

All refinements were based on least-squares fits of the intensities, although radial distribution curves were calculated to help monitor the structure analyses.

The assumptions and geometric constraints imposed followed closely

TABLE 1

Experimental conditions under which diffraction patterns were recorded

\begin{tabular}{lccc}
\hline Nozzle-to-plate distance (cm) & 21.460 & 10.302 & 6.862 \\
Diameter of nozzle tip (mm) & 0.29 & 0.29 & 0.29 \\
Nozzle-to-beam distance (mm) & 0.55 & 0.55 & 0.55 \\
Sample reservoir temp. (C $\left.{ }^{\circ}\right)$ & 85 & 85 & 85 \\
Estimated sample pressure (torr) & 8 & 8 & 8 \\
Sector used (radius, mm) & $r^{3}(48)$ & $r^{3}(48)$ & $r^{3}(48)$ \\
Exposure time (s) & 10 & 43 & 120 \\
No. plates used & 5 & 4 & 5 \\
Accelerating voltage (kv) & 40 & 40 & 40 \\
\hline
\end{tabular}


those for TTBM [1], namely overall $C_{3}$ symmetry, local $C_{3}$ symmetry for the t-butyl groups, and local $C_{3 \mathrm{v}}$ symmetry for methyl groups. After much trial and error, having established the three different bond lengths, three principal bond angles, and two torsions (see ref. 1), one additional parameter, a tilt angle, was varied. This tilt was taken to be the angle between the imaginary $C_{3}$ axis of each $\left(\mathrm{CH}_{3}\right)_{3} \mathrm{C}$ group and the associated interior $\mathrm{C}-\mathrm{Si}$ bond line; this imaginary axis was confined to the $\mathrm{H}-\mathrm{Si}-\mathrm{C}$ plane. A positive value of the tilt corresponds to a better avoidance of the methyl groups trans to the $\mathrm{Si}-\mathrm{H}$ bond. An even more general description would have allowed the imaginary $C_{3}$ axis to leave the $\mathrm{H}-\mathrm{Si}-\mathrm{C}$ plane or would have permitted the t-butyl group to deviate from local $C_{3}$ symmetry. It was believed that the diffraction information was too limited to establish the number of independent parameters implied by this additional flexibility, however.

In a concurrent diffraction analysis of $\left[\left(\mathrm{CH}_{3}\right)_{3} \mathrm{Si}\right]_{3} \mathrm{SiH}[10]$, it became apparent that the $\left(\mathrm{CH}_{3}\right)_{3} \mathrm{Si}$ - torsional parameter was marginally determined. The value to which it converged depended upon the initial assumptions made about certain amplitudes of vibration (particularly those for the $C \cdots C(I, V)$ distances). Since it proved to be impractical to refine these structural and vibrational parameters independently, it was decided to develop a reasonable molecular force field for the purpose of calculating amplitudes of vibration. Normal coordinate analyses were performed using the method of Hilderbrandt and Weiser [11]. Selected calculated amplitudes were then adopted as constraints in the refinements. Similar situations have been encountered before [12]. Added benefits of this treatment are that such calculations can also provide shrinkage corrections. Refinements both including and excluding shrinkage corrections were carried out.

Once the crucial calculated amplitudes had been incorporated into the structure refinements the $\left(\mathrm{CH}_{3}\right)_{3} \mathrm{Si}$ - torsional parameter converged to the same value, irrespective of its starting value. In the case of TTBS a similar multiminimum least-squares surface was not encountered and various starting points refined to a common minimum.

Refinements gave a marginally lower standard deviation if the methyl torsional magnitude was allowed to vary (though refinements were blind to the sign). Nevertheless, depending upon assumed amplitudes, etc., torsional magnitudes up to $16^{\circ}$ were encountered, and these had large standard deviations. Because such torsions appear to be unreasonable, final refinements froze the methyl torsions at $4.2^{\circ}$.

To help identify the parameters, the numbering scheme for atoms is shown in Fig. 1. Reduced molecular intensity curves are plotted in Fig. 2 and a radial distribution curve is presented in Fig. 3. Tabulations of data relevant to the analysis are available*.

\footnotetext{
*Lists of experimental leveled intensities, background functions and matrices of correlation coefficients pertaining to the least-squares refinements, together with amplitudes of vibration $l_{i j}$ and quantities $K_{i j}$ associated with shrinkage corrections calculated according to the silane force field have been deposited with the British Library at Boston Spa, Yorkshire, LS23 7 BQ (Gt. Britain) as Supplementary Publication No. SUP 26141 (11 pages).
} 


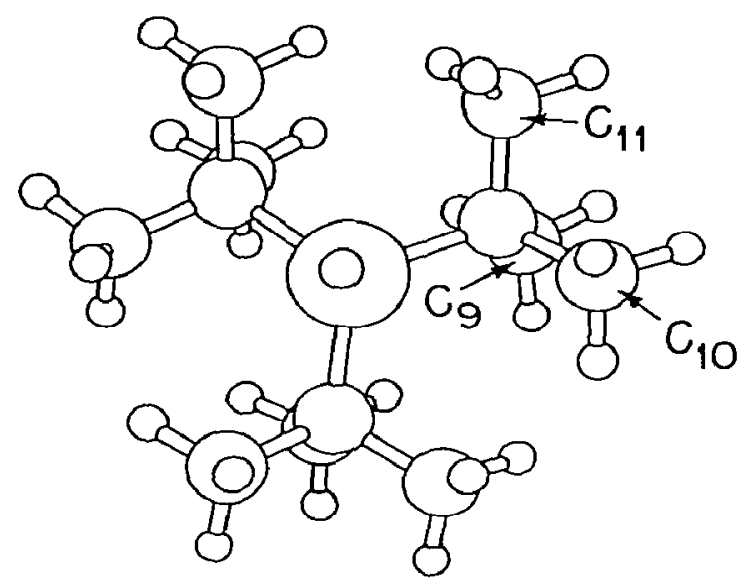

Fig. 1. Numbering scheme for carbon atoms in twisted tert-jutyl groups of tri-tertbutylsilane.

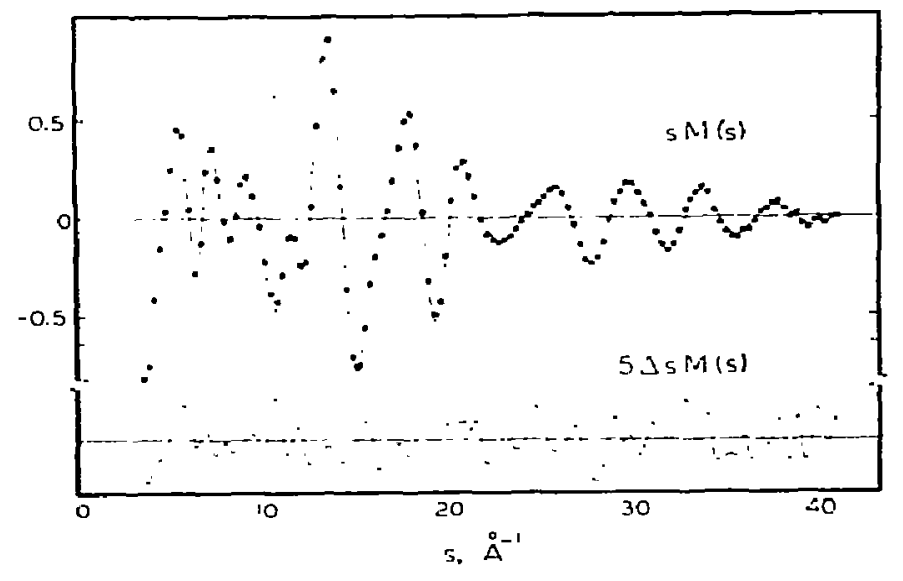

Fig. 2. Experimental ( $\overline{\mathrm{d}} \mathrm{t}$ s) and calculated (smooth curve) molecular intensity function for tri-tert-butylsilane. $\Delta s M=s M_{\text {exp }}-s M_{\text {calc }}$ -

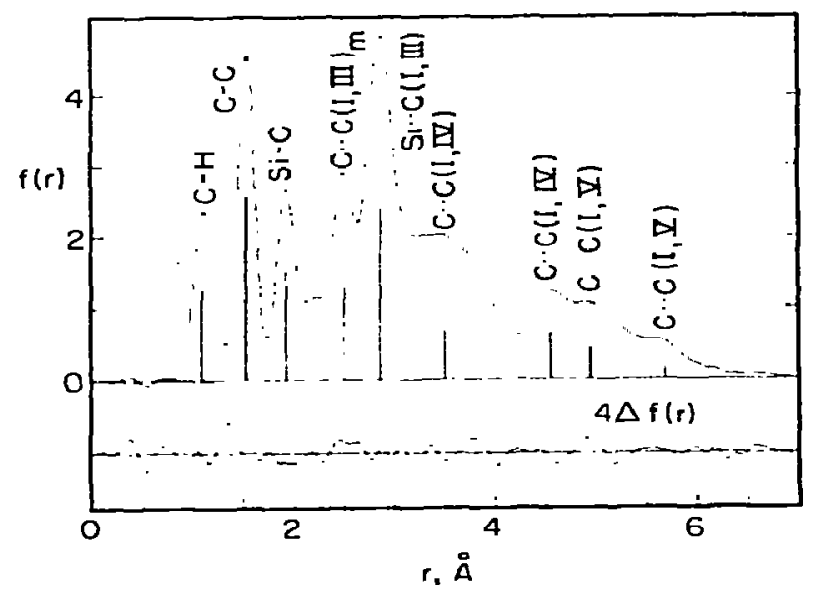

Fig. 3. Experimental radial distribution function for tri-tert-butylsilane. $\Delta f=f_{\text {exist }}-$ $f_{\text {calc- }}$ 


\section{SILANE FORCE FIELD}

The need to develop a molecular force field for calculation of amplitudes of vibration and shrinkage corrections in organosilicon molecules was pointed out in the previous section. Because of the potential use of this technique in crowded molecules it seemed appropriate to adopt as a basis the MUB-2 field which, though simple, has been particularly successful in accounting for steric effects. Extension of the hydrocarbon field to include silicon requires the additional formulation of $\mathrm{Si} \cdots \mathrm{H}, \mathrm{Si} \cdots \mathrm{C}$, and $\mathrm{Si} \cdots \mathrm{Si}$ non-bonded interactions, as well as the usual stretch, bend, and torsional contributions. Firstly, the new non-bonded functions, incorporating hydrogen foreshortening $[5,13]$, were constructed to give non-bonded force curves similar to those for hydrocarbons, with allowance for the additional van der Waals radius of silicon. As befits a Urey-Bradley field, these interactions were chosen to be appropriate even down to the distances encountered in geminal interactions. Once these functions had been selected, the required valence stretch and bend force constants were taken from the literature [14] and converted into Urey-Bradley constants compatible with the non-bonded functions. As in the MUB-1 and MUB-2 fields, all reference bond angles were chosen simply to be the tetrahedral angle, in the expectation (well satisfied in hydrocarbons) that structural variations from this angle can be accounted for by appropriate non-bonded interactions (geminal and others). Reference $\mathrm{Si}-\mathrm{H}, \mathrm{Si}-\mathrm{C}$, and $\mathrm{Si}-\mathrm{Si}$ lengths were chosen to reproduce the experimental bond lengths in $\mathrm{CH}_{3} \mathrm{SiH}_{3}$ [15] and $\mathrm{Si}_{2} \mathrm{H}_{6}$ [16] in the presence of the substantial geminal non-bonded forces adopted. Calculated bond angles, for which no parameters were adjusted, agreed with experimental bond angles in these reference compounds to within perhaps twice the experimental standard deviations. Torsional barrier parameters were selected to reproduce, together with the non-bonded interactions, the reported barriers for $\mathrm{CH}_{3} \mathrm{SiH}_{3}[15]$ and $\mathrm{Si}_{2} \mathrm{H}_{6}[17,18]$.

Parameters for the silane force field are listed in Table 2. The attention paid to parameter optimization in the present extension to silanes was much less than in the original MUB-2 formulation. Nevertheless, the field should yield reasonable mean amplitudes and shrinkage corrections.

\section{DISCUSSION}

A rough assessment of the validity of the model force field used in calculations of shrinkage corrections can be made by comparing the calculated amplitudes in Table 3 with those derived from scattered intensities. The differences are of the magnitude expected from uncertainties in the diffraction data. Refinements made with and without shrinkage gave bond lengths agreeing within a standard deviation. Bond angles showed more variation, as expected, the largest changes introduced by shrinkage corrections being decreases in $\angle \mathrm{HCC}$ of $0.8^{\circ}$, in the t-butyl tilt of $0.7^{\circ}$ and in the t-butyl torsion of $0.6^{\circ}$. Other angles changed by less than $0.5^{\circ}$. 


\section{TABLE 2}

Parameters for silane force field ${ }^{a}$

\begin{tabular}{|c|c|c|c|c|c|}
\hline \multicolumn{6}{|c|}{ Non-bonded $V(q)=A e^{-\alpha q}-B q^{-6}$} \\
\hline Parameter & $A$ & $\alpha$ & $\boldsymbol{B}$ & & Foreshortening \\
\hline$H \cdot H$ & 14.72 & 3.40 & 0.3333 & & - \\
\hline$H \ldots C$ & 135.5 & 3.75 & 1.076 & & 0.117 \\
\hline $\mathbf{C} \cdot \mathbf{C}$ & 502.2 & 3.75 & 2.779 & & - \\
\hline $\mathrm{Si} \ldots \mathrm{H}$ & 145.9 & 3.28 & 1.915 & & 0.117 \\
\hline $\mathrm{Si} \cdot \mathrm{C}$ & 833.7 & 3.46 & 5.529 & & - \\
\hline $\mathrm{Si} \cdot \mathrm{Si}_{\mathbf{i}}$ & 1167.2 & 3.16 & 11.0 & & - \\
\hline \multicolumn{6}{|c|}{ Bond stretching $^{\mathrm{b}} V(r)=\frac{1}{2} K\left(r-r^{0}\right)^{2}-\frac{1}{2} K a\left(r-r^{0}\right)^{3}$} \\
\hline Parameter & $K$ & ro & Parameter & $K$ & $r^{0}$ \\
\hline $\mathbf{C}-\mathbf{H}$ & 3.85 & 1.0203 & $\mathrm{Si}-\mathrm{C}$ & 2.00 & 1.636 \\
\hline $\mathrm{C}-\mathrm{C}$ & 2.34 & 1.166 & $\mathrm{Si}-\mathrm{Si}$ & 1.60 & 2.273 \\
\hline $\mathrm{Si}-\mathrm{H}$ & 2.50 & 1.472 & & & \\
\hline
\end{tabular}

Angle bending $V=\frac{1}{2} H\left(\theta-\theta^{0}\right)^{2}$

\begin{tabular}{llllll}
\hline Parameter & $H$ & $\theta^{0}$ & Parameter & $H$ & $\theta^{\circ}$ \\
\hline H-C-C & 0.350 & 1.91063 & H-Si-Si & 0.563 & 1.91063 \\
H-C-C & 0.322 & 1.91063 & Si-C-C & 0.259 & 1.91063 \\
C-C-CC & 0.629 & 1.91063 & C-Si-C & 0.418 & 1.91063 \\
H-Si-H & 0.395 & 1.91063 & Si-Si-C & 0.400 & 1.91063 \\
H-Si-C & 0.277 & 1.91063 & Si-Si-Si & 0.400 & 1.91063 \\
H-C-Si & 0.209 & 1.91063 & & & \\
\hline
\end{tabular}

Torsion $V(\tau)=\frac{1}{2} V_{3}(1+\cos 3 \tau)$

Parameter $V_{3}\left(\mathrm{kcal} \mathrm{mol}^{-1}\right)$

\begin{tabular}{ll}
\hline$-\mathrm{C}-\mathrm{C}-$ & $2.73^{\mathrm{c}}$ \\
$-\mathrm{C}-\mathrm{Si}-$ & 1.60 \\
$-\mathrm{Si}-\mathrm{Si}-$ & $0.57^{\mathrm{d}}-1.22^{\mathrm{e}}$ \\
\hline
\end{tabular}

${ }^{a}$ Units, exclusive of $V_{3}$, are such that energies are in mdyn $A$, angles in radians, and distances in Angstrom units. ${ }^{b} a$, the Morse parameter, is $\approx 1.8 \mathrm{~A}^{-1} .{ }^{\mathrm{c}}$ Modified from that in ref. 5 to compensate for a numerical error. ${ }^{d}$ Ref. $17 .{ }^{e}$ Ref. 18.

The most interesting question to be answered about tri-tert-butylsilane is the degree to which the steric stress, so conspicuous in tri-tert-butylmethane, is manifested in the structure. Presumably the greater clearance between t-butyl groups in the silane implies a lower stress than in the methane derivative. This change cannot, however, be perceived in the strain component relieving the stress most easily, namely the t-butyl torsion. In the four compounds $\left[\left(\mathrm{CH}_{3}\right)_{3} \mathrm{X}\right]_{3} \mathrm{YH}$, with $\mathrm{X}$ and $\mathrm{Y}$ representing $\mathrm{C}$ or $\mathrm{Si}$, there is a 
TABLE 3

Experimental and calculated structural parameters ${ }^{\mathrm{a}}$ of $\left[\left(\mathrm{CH}_{3}\right)_{3} \mathrm{C}\right]_{3} \mathrm{SiH}$

\begin{tabular}{|c|c|c|c|c|}
\hline \multirow[t]{2}{*}{ Parameter } & \multicolumn{2}{|c|}{ Experimental } & \multicolumn{2}{|c|}{ Calculated } \\
\hline & $r_{\mathbf{g}}$ & $l_{\mathbf{g}}$ & $r$ & $l^{0}$ \\
\hline $\mathrm{Si}-\mathbf{H}$ & 1.49 & 0.09 & 1.491 & 0.091 \\
\hline $\mathrm{Si}-\mathrm{C}$ & $1.934(6)$ & $0.061(5)$ & 1.922 & 0.053 \\
\hline $\mathrm{C}-\mathrm{C}$ & $1.548(3)$ & $0.054(3)$ & 1.535 & 0.052 \\
\hline $\mathbf{C}-\mathrm{H}$ & $1.121(9)$ & $0.080(7)$ & 1.110 & 0.080 \\
\hline $\mathrm{C} \cdot \boldsymbol{H}(\mathrm{I}, \mathrm{III})$ & 2.20 & $0.103(13)$ & & 0.12 \\
\hline $\mathrm{C} \cdot \boldsymbol{H}(\mathbf{I}, \mathbf{I V})$ & $2.69-4.10$ & $0.170(22)$ & & 0.16 \\
\hline $\mathrm{Si}-\mathrm{H}(\mathrm{I}, \mathrm{IV})$ & $2.99-3.90$ & $0.226(52)$ & & 0.14 \\
\hline $\mathrm{Si}-\mathrm{C}(\mathrm{I}, \mathrm{III})$ & $2.86-2.93$ & $0.100(10)$ & & 0.070 \\
\hline$C \cdot C(I, I I I)$ & 2.49 & $0.078(6)$ & & 0.075 \\
\hline $\mathrm{C} \cdot \mathrm{C}(\mathrm{I}, \mathrm{IV}) \mathrm{T}$ & 4.56 & $0.141(18)$ & & 0.090 \\
\hline $\mathrm{C} \cdot \mathrm{C}(\mathrm{I}, \mathrm{V}) T T$ & 5.69 & $0.136(35)$ & & 0.10 \\
\hline $\mathrm{C} \cdot \mathrm{C}(\mathrm{I}, \mathrm{V}) \mathrm{TG}$ & $4.55-5.20$ & $0.164(49)$ & & 0.13 \\
\hline $\mathrm{C} \cdot \mathrm{C}(\mathrm{I}, \mathrm{V}) G G$ & $3.67-3.88$ & $0.214(49)$ & & 0.18 \\
\hline$\angle \mathrm{HSiC}$ & \multicolumn{2}{|c|}{$105.3(1.3)$} & \multicolumn{2}{|c|}{103.5} \\
\hline$\angle \mathrm{SiCC}$ & \multicolumn{2}{|c|}{$111.5(0.5)$} & \multicolumn{2}{|c|}{$\begin{array}{l}111.1(\mathrm{C} 9-\mathrm{C} 6-\mathrm{Si} 2) \\
110.5(\mathrm{C} 10-\mathrm{C} 6-\mathrm{Si} 2) \\
111.5(\mathrm{C} 11-\mathrm{C} 6-\mathrm{Si2})\end{array}$} \\
\hline$\angle \mathrm{CCH}$ & \multicolumn{2}{|c|}{$110.0(1.5)$} & \multicolumn{2}{|c|}{112.4} \\
\hline$\tau$ (t-butyl) & \multicolumn{2}{|c|}{$10.0(3.1)$} & \multicolumn{2}{|c|}{15.9} \\
\hline$\tau$ (methyl) & \multicolumn{2}{|c|}{$4.2^{\mathrm{c}}$} & \multicolumn{2}{|c|}{$4.2 \mathrm{~d}$} \\
\hline Tilt (t-butyl)e & \multicolumn{2}{|c|}{$2.7(2.4)$} & \multicolumn{2}{|c|}{1.2} \\
\hline$\sigma(I) / I=0.00068^{f}$ & & & & \\
\hline
\end{tabular}

${ }^{2}$ Distances and amplitudes are in $\AA$, angles and dihed ral angles are in degrees. Torsional angles are measured with respect to staggered conformations. ${ }^{b}$ Average value. ${ }^{c}$ Parameter not varied in least-squares refinements. ${ }^{\mathrm{d}}$ The average of absolute vaiues is used. ${ }^{e}$ For definition, see text. Experimental tilt constrained as in text. For direction of calculated tilt, see footnote, Table $4 .{ }^{\mathrm{f}}$ Relative standard deviation of intensities (sM (s) was weighted uniformly).

wide variation in stress, yet molecular mechanics calculations (Table 4) show that, in all cases, bumps fit naturally into hollows at a torsional twist of $15-17^{\circ}$. The spread is smaller than the uncertainty in the experimental torsional parameter. Imposing the above constraints in the analysis, both the TTBS and TTBM torsions, while clearly indicative of steric stress, are a few degrees smaller than the molecular mechanics values. A glance at Table III of ref. 2 reveals that this parameter is rather sensitive to constraints.

A more discriminating parameter is $\angle \mathrm{HSiC}$, which is compressed to 105.3 $\pm 1.3^{\circ}(3 \sigma)$ (experiment) or $103.5^{\circ}$ (molecular mechanics). Corresponding angles in TTBM are $101.6 \pm 1.2^{\circ}$ or $101.9^{\circ}$, demonstrating the lesser, but still rather considerable strain present in the silyl compound. 
TABLE 4

Structures of $\left[\left(\mathrm{CH}_{3}\right)_{3} \mathrm{X}\right]_{3} \mathrm{YH}$ molecules calculated via the force field of Table $2^{\mathrm{a}}$

\begin{tabular}{|c|c|c|c|c|}
\hline Parameter & {$\left[\left(\mathrm{CH}_{3}\right)_{3} \mathrm{C}\right]_{3} \mathrm{CH}$} & {$\left[\left(\mathrm{CH}_{3}\right)_{3} \mathrm{C}\right]_{3} \mathrm{SiH}$} & {$\left[\left(\mathrm{CH}_{3}\right)_{3} \mathrm{Si}\right]_{3} \mathrm{CH}$} & {$\left[\left(\mathrm{CH}_{3}\right)_{3} \mathrm{Si}\right]_{3} \mathrm{SiH}$} \\
\hline $\mathbf{H}-\mathbf{Y}$ & 1.1159 & 1.4909 & 1.1086 & 1.4854 \\
\hline $\mathbf{Y}-\mathrm{X}$ & 1.6051 & 1.9219 & 1.8998 & 2.3316 \\
\hline $\mathbf{X}-\mathbf{C}^{\mathbf{b}}$ & 1.5447 & 1.5353 & 1.8709 & 1.8674 \\
\hline $\mathrm{C}-\mathrm{H}^{\mathbf{b}}$ & 1.1083 & 1.1102 & 1.1069 & 1.1076 \\
\hline $\begin{array}{l}\angle \mathrm{HYX} \\
\angle \mathrm{YXC}\end{array}$ & 102.1 & 103.5 & 104.7 & 108.2 \\
\hline$i=9$ & 115.02 & 111.08 & 112.74 & 110.53 \\
\hline$i=10$ & 112.48 & 110.47 & 110.50 & 110.10 \\
\hline$i=11$ & 111.34 & 111.51 & 113.40 & 109.50 \\
\hline$\angle \mathrm{XCH}{ }^{\mathrm{b}}$ & 112.9 & 112.4 & 111.6 & 111.5 \\
\hline$\tau(\mathrm{HYXC})$ & 17.3 & 15.9 & 17.1 & 14.7 \\
\hline$\tau\left(\mathrm{YXC} \mathrm{C}_{i} \mathrm{H}\right)$ & $4.5^{\mathrm{c}}$ & $4.4^{\mathrm{c}}$ & $6.4^{\mathrm{c}}$ & $2.4^{c}$ \\
\hline$i=9$ & 2.09 & 2.76 & 3.26 & 1.76 \\
\hline$i=10$ & 2.03 & -4.95 & -10.24 & 3.16 \\
\hline$i=11$ & -9.48 & 5.68 & 5.84 & -1.69 \\
\hline$\left(\mathrm{CH}_{3}\right)_{3} \mathrm{X}$ tillt & 2.46 & 1.20 & 3.39 & 0.85 \\
\hline Tilt azimuth & -32.4 & 87.2 & 81.1 & -55.0 \\
\hline
\end{tabular}

${ }^{a}$ Distances in $\AA$, angles in degrees. ${ }^{b}$ A verage. ${ }^{c}$ Average of absolute values. ${ }^{d}$ Azimuthal angle is the dihedral angle between plane $C_{9} X E$ and plane $X E Y$, where $X E$ is the effective $C_{3}$ axis of the $\left(\mathrm{CH}_{3}\right)_{3} \mathrm{X}$ group. A positive value means that $\tau\left(\mathrm{C}_{1}, \mathrm{XEY}\right)>$ $\tau\left(\mathrm{C}_{10} \mathrm{XEY}\right)$. It is helpful to envisage $\mathrm{E}$ as a dummy atom on the $C_{3}$ axis close to $\mathrm{Y}$.

A still more striking confirmation of the strong steric stress is seen in the central $\mathrm{Si}-\mathrm{C}$ bond lengths. In the hierarchy of parameters whose relaxation is assumed to relieve steric stress, torsions are usually considered to be the most compliant and effective, followed by bond angle bends. Bond stretches or compressions, being energetically costly, are often disregarded. Yet the present study shows that the central bonds are $0.06 \AA$ (experiment) or $0.05 \AA$ (molecular mechanics) longer than $\mathrm{Si}-\mathrm{C}$ bonds in trimethylsilane [19]. Corresponding stretches in TTBM are $0.08 \AA$ or $0.07 \AA$, in comparison with isobutane [20]. Again, the strain in TTBS, while substantial, is smaller than in TTBM, despite a lower force constant in TTBS (see Table 2). Another profitable comparison is between TTBS and its isoelectronic analog, tri-tert-butylphosphine (TTBP). In TTBP the $\mathbf{C}-\mathbf{P}$ bond is reported [21] to be $0.07 \AA$ longer than that in trimethylphosphine [22] .

Overall, the agreement between the experimental and calculated structures presented in Table 3 is quite satisfactory, including the steric deformations from idealized reference structures. It therefore seems of interest to tabulate 
the structures of the other two closely related compounds, $\left[\left(\mathrm{CH}_{3}\right)_{3} \mathrm{Si}\right]_{3} \mathrm{CH}$ (TTSM) and $\left[\left(\mathrm{CH}_{3}\right) \mathrm{Si}\right]_{3} \mathrm{SiH}$ (TTSS), as predicted by the present extension of the MUB-2 force field. This is done in Table 4. It appears that TTSM is slightly less strained than TTBS, but several-fold more strained than TTSS.

In view of the preliminary success obtained with the simply-parameterized model force field described above, it would seem worthwhile to optimize the silane components by a more comprehensive set of adjustments, such as those described elsewhere [5] for MUB-2. It is apparent that realistic model force fields can play an extremely useful role in structural chemistry, firstly, in augmenting diffraction analyses by affording calculated amplitudes of vibration and shrinkage corrections and, secondly, in yielding, simply and inexpensively, predicted structures and thermodynamic quantities [23].

\section{ACKNOWLEDGEMENTS}

This research was supported by a grant from the National Science Foundation. We gratefully acknowledge a generous allowance of computing time from the University of Michigan Computing Center. We thank Dr. P. H. Nowakowski and Prof. L. M. Sommer for donating the sample of tri-tertbutylsilane.

\section{REFERENCES}

1 H. B. Burgi and L. S. Bartell, J. Am. Chem. Soc., 94 (1971) 5236.

2 L. S. Bartell and H. B. Burgi, J. Am. Chem. Soc., 94 (1971) 5239.

3 M. P. Doyle and C. T. West, J. Am. Chem. Soc., 97 (1975) 3777; E. M. Dexheimer and L. Spialter, Tetrahedron Lett., 22/23 (1975) 1771.

4 E. J. Jacob, H. B. Thompson and L. S. Bartell, J. Chem. Phys., 47 (1967) 3736.

5 S. Fitzwater and L. S. Bartell, J. Am. Chem. Soc., 98 (1976) 5107.

6 I. Hargittai, J. Hernadi, M. Kolonito and L. Spialter, Rev. Sci. Instrum., 42 (1971) 546.

7 L. S. Bartell in A. Weissberger and B. W. Rossiter (Eds.), Physical Methods in Chemistry, 4th edn., Interscience, New York, 1972.

8 L. Schäfer, A. C. Yates and R. A. Bonham, J. Chem. Phys., 55 (1971) 3055.

9 C. Tavard, D. Nicolas and M. Rouault, J. Chim. Phys., 64 (1967) 540.

$10 \mathrm{~S}$. K. Doun, Thesis, University of Michigan, 1979. Irregularities were encountered in the analyses, possibly because of decomposition products, ruling out publication.

11 R. L. Hilderbrandt and J. D. Weiser, J. Chem. Phys., 55 (1971) 4648.

12 J. D. Weiser, D. C. Moody, J. C. Huffman, R. L. Hilderbrandt and R. Schaeffer, J. Am. Chem. Soc., 97 (1975) 1074; R. L. Hilderbrandt, G. D. Homer and P. Bondjouk, J. Am. Chem. Soc., 98 (1976) 7476.

13 D. Williams, J. Chem. Phys., 43 (1965) 4424.

14 H. Michiro, Bull. Chem. Soc. Jpn., 46 (1973) 2044 ; 45 (1972) 732 ; C. F. Hoefler, Monatsh. Chem., 107 (1976) 893.

15 R. W. Kilb and L. Pierce, J. Chem. Phys., 27 (1957) 108.

16 B. Beagley, A. R. Conrad, J. M. Freeman, J. J. Monagham, B. C. Norton and G. C. Holywell, J. Mol. Struct., 11 (1972) 371.

17 M. Pfeiffer and H. J. Spangenberg, Z. Phys. Chem., 232 (1966) 47.

18 A. Hinchliffe, J. Mol. Struct., 48 (1978) 279. 
19 A. C. Bond and L. O. Brockway, J. Am. Chem. Soc., 76 (1954) 3312.

20 R. L. Hilderbrandt and J. D. Weiser, J. Mol. Struct., 15 (1973) 27.

21 H. Oberhammer, R. Schmutzler and O. Stelzer, Inorg. Chem., 17 (1978) 1255.

22 L. S. Bartell, J. Chem. Phys., 32 (1960) 512.

23 For other illustrations of the role of model force fields as applied to $\left[\left(\mathrm{CH}_{3}\right)_{3} \mathrm{X}\right]_{3} \mathrm{Y}$ molecules, see W. D. Hounshell, L. D. Iroff, R. J. Wroczynski and K. Mislow, J. Am. Chem. Soc., 100 (1978) 5212; R. J. Wroczynski, L. D. Iroff and K. Mislow, J. Org. Chem., 43 (1978) 4236; R. J. Wroczynski and K. Mislow, J. Am. Chem. Soc., 101 (1979) 3980 , and refs. therein. 